\title{
KARAKTERISTIK IBU YANG BERHUBUNGAN DENGAN PERDARAHAN POST PARTUM DI RB MEDIKA UTAMA WONOKUPANG BALONGBENDO SIDOARJO TAHUN 2009
}

\author{
Sarmini Moedjiarto \\ Dosen Politeknik Kesehatan Majapahit Mojokerto
}

\begin{abstract}
ABSTRAK
Perdarahan post partum merupakan salah satu komplikasi persalinan yang dapat di pengaruhi oleh berbagai penyebab. Salah satu penyebab terjadinya perdarahan post partum yaitu jarak persalinan. Jarak persalinan yang terlalu dekat maupun terlalu jauh dapat beresiko terjadi perdarahan post partum. Permasalahan yang dikaji dalam penelitian ini adalah adakah hubungan jarak persalinan dengan perdarahan post partum. Tujuan dari penelitian ini adalah untuk mengetahui hubungan jarak persalinan dengan perdarahan post partum.

Jenis penelitian yang di gunakan adalah analitik dengan rancang bangun cross sectional. Variabel independenya jarak persalinan dan varibel dependenya adalah perdarahan post partum. Populasinya adalah semua ibu bersalin di RB Medika Utama Wonokupang kecamatan Balongbendo Kabupaten Sidoarjo pada 1 Januari-31 Desember 2009 sebanyak 386 ibu bersalin. Jumlah sampel sebanyak 386 ibu bersalin dengan pengambilan sampel non probability sampling dengan teknik total sampling di mulai tanggal $22 \mathrm{Mei}-22$ Juni 2010. Jenis pengumpulan data berupa data sekunder melalui observasi dengan instrumen ckeck list. Uji statistik yang di gunakan adalah exact fisher.

Hasil penelitian di peroleh bahwa dari semua ibu bersalin yang memiliki jarak persalinan kurang dari 2 tahun adalah sebanyak 42 responden $(10,8 \%)$ dan yang memiliki jarak persalinan $\geq 2$ tahun sebanyak 344 responden ( $89,2 \%$ ). Dan ibu bersalin yang mengalami perdarahan post partum sebanyak 33 responden $(8,6 \%)$ dan yang tidak perdarahan post partum sebanyak 353 responden ( 91,4\%).42 responden yang memiliki jarak persalinan kurang dari 2 tahun yang mengalami perdarahan post partum sebanyak 12 responden $(3,1 \%)$ dan yang tidak mengalami perdarahan post partum sebanyak 30 responden $(7,7 \%)$

Uji statistik yang di lakukan adalah uji statistik exact fisher dengan hasil $\mathrm{p}=0,000$. Hasil nilai uji Fisher exact $0,000<\mathrm{p}<0,05$ maka Ho ditolak, $\mathrm{H}_{1}$ diterima artinya ada hubungan yang bermakna antara variabel independen (jarak persalinan) dan variabel dependen ( perdarahan post partum).

Kesimpulan dari penelitian ini adalah bahwa jarak persalinan merupakan salah satu penyebab predisposisi terjadinya perdarahan post partum. Perlu adanya penanganan obstetrik yang efisian dalam pemantauan kehamilan agar komplikasi persalinan terhadap perdarahan post partum bisa di cegah.
\end{abstract}

Kata Kunci : Jarak Persalinan, Perdarahan Post Partum

\section{A. PENDAHULUAN}

Kehamilan merupakan salah satu hal yang harus mendapatkan perawatan cukup dalam perkembangan janin, perawatan antenatal mempunyai tujuan untuk mengusahakan agar ibu dan sampai pada akhir kehamilan sama sehatnya atau lebih sehat dari pada sebelum hamil. (Jones, $2002: 35$ ).

Kehamilan dan persalinan merupakan proses alami, tetapi bukannya tanpa resiko dan merupakan beban bagi seorang wanita. Ibu dapat mengalami keluhan fisik dan mental, sebagian kecil mengalami kesukaran selama kehamilan dan persalinan. Salah satu resiko yang dapat menyebabkan komplikasi pasca persalinan yaitu jarak persalinan (Poedji Rochjati, 2003 :56).

Ibu hamil dengan jarak kelahiran dengan anak terkecil (kurang dari 2 tahun) untuk kesehatan fisik dan rahim masih butuh istirahat. Ada kemungkinan ibu masih menyusui, selain itu anak tersebut masih butuh asuhan dan perhatian orang tuanya. Bahaya yang dapat terjadi 
antara lain persalinan yang belum cukup bulan, bayi dengan berat badan rendah kurang dari 2500 gram (Poedji Rochjati, 2003 :56).

Jarak persalinan yang sehat adalah 2-5 tahun yang aman diharapkan dapat mengembalikan fungsi-fungsi alat-alat kandungan (involusio). Jika jarak persalinan kurang dari 2 tahun atau lebih dari 5 tahun maka dapat mengakibatkan kematian maternal lebih besar yang diawali dengan berbagai penyulit diantaranya perdarahan post partum salah satunya (Poedji Rochjati, 2003 : 57).

Perdarahan post partum adalah salah satu resiko terbesar yang menyebabkan terjadinya kematian maternal. Frekuensi perdarahan post partum di Amerika Serikat sekitar 5-10\%. Dan dari laporan - laporan baik di negara maju dan negara berkembang angka kejadian berkisar antara 5\%-15\%. dan di Indonesia komplikasi perdarahan post partum 5,1\% dari seluruh persalinan (Admin, 2009: 1).

Berdasarkan pembangunan kesehatan Indonesia yang telah dicapai sampai tahun 2008, terdapat AKI (Angka Kematian Ibu) sebesar 248/100.000 KH/Kelahiran Hidup. Jumlah kematian ini masih tinggi dan jauh dibawah standart yang ditetapkan oleh pemerintah Indonesia untuk tahun 2010 yaitu menurunkan AKI sebesar 125/100.000 Kelahiran Hidup. Selain faktor kemiskinan dan masalah aksesibilitas penanganan kelahiran $75 \%$ hingga $85 \%$ kematian maternal disebabkan karena obstetrik langsung terutama akibat perdarahan. Padahal dari $90 \%$ dari kematian itu bisa dihindari (Depkes, 2009:1).

Angka Kematian Ibu (AKI) di Propinsi Jawa Timur pada tahun 2008 terdapat 690.282 jumlah ibu hamil, dari jumlah kelahiran terdapat 357 kasus kematian ibu maternal, yang terjadi pada saat kehamilan 65 orang, kematian ibu saat bersalin 221 orang, dan kematian ibu nifas 68 orang (Dinkes JATIM, $2008: 1$ ).

Jumlah kematian ibu di Sidoarjo saat melahirkan meningkat dari 91,3/100.000 kelahiran hidup, pada tahun 2007 menjadi 112,6/100.000 kelahiran hidup. Peningkatan Angka Kematian Ibu (AKI) terjadi lantaran keterlambatan rujukan ke rumah sakit yang dilakukan petugas pembantu persalinan ibu, rendahnya asupan gizi yang dipengarui ekonomi rendah (Dinkes Sidoarjo, $2008: 1$ ).

Perdarahan pasca persalinan adalah sebab penting kematian ibu, 25\% kematian ibu disebabkan karena perdarahan. Dari penyebab perdarahan tersebut, perdarahan post partum yang paling sering. Bahkan 4 kali lebih tinggi dibandingkan perdarahan antepartum. Perdarahan post partum (HPP) disebabkan karena hal-hal berikut antara lain : (1). Atonia Uteri (50\%-60\%) yang disebabkan karena proses persalinan yang lama, pembesaran uterus berlebih pada waktu hamil/overdistensi uterus (pada hamil kembar/janin besar), persalinan yang sering atau multiparitas, anastesi yang dalam. (2). Retensio plasenta (16\%-17\%) yang disebabkan karena implantasi plasenta yang terlalu dalam pada dinding uterus. (3). Sisa plasenta (23\%-24\%) karena ada selaput plasenta/lobus yang tertinggal dalam uterus. (4). Laserai jalan lahir(4\%-5\%) dapat terjadi jika robekan lebar dan dalam, lebih-lebih jika mengenai pembuluh darah dapat menimbulkan perdarahan yang hebat. (5). Kelainan darah $(0,5 \%-0,8 \%)$ karena kelainan proses pembekuan darah akibat hipofibrinogenemia (Solusio plasenta, Retensio janin mati dalam uterus, Emboli air ketuban) (Admin, $2009: 1$ ).

Perdarahan post partum dapat terjadi tiba - tiba dan bahkan sangat lambat, perdarahan sedang tetapi menetap dapat berlanjut dalam beberapa hari/minggu. Perdarahan dapat terjadi dini selama 24 jam setelah melahirkan atau lambat 24 jam setelah melahirkan, sampai hari ke 28 post partum (Bobak dkk, 2004;664).

Upaya bidan untuk menangani perdarahan yaitu dengan meningkatkan upaya preventif seperti meningkatkan penerimaan keluarga berencana (KB) sehingga memperkecil jumlah grandemultipara dan memperpanjang jarak kehamilan. Melakukan konsultasi terhadap kehamilan ganda/dugaan janin besar (makrosomia) dan mengurangi peranan pertolongan persalinan oleh dukun tidak terlatih.

Berdasarkan data rekam medis yang diperoleh dari Rumah Bersalin Medika Utama Wonokupang, Kecamatan Balong Bendo, Kabupaten Sidoarjo didapatkan data tahun 2008 
yaitu jumlah persalinan didapat 572 persalinan dengan 366 persalinan normal $(63,98 \%)$ dan 206 perabdominal $(36,01 \%), 29$ persalinan $(5,06 \%)$ mengalami perdarahan post partum.

Berdasarkan fenomena diatas yaitu kejadian perdarahan post partum sebanyak $5.06 \%$ merupakan angka yang tergolong tinggi pada kejadian patologi persalinan. Oleh sebab itu peneliti ingin meneliti lebih lanjut tentang hubungan jarak persalinan dengan perdarahan post partum di Rumah Bersalin Medika Utama Wonokupang, Kecamatan Balongbendo, Sidoarjo tahun 2009.

\section{B. TINJAUAN PUSTAKA}

1. Konsep Dasar Jarak Persalinan

a. Pengertian

1) Jarak persalinan adalah waktu antara persalinan terakhir dengan kehamilan sekarang (Mufdlilah, 2009 : 71).

2) Jarak persalinan adalah jarak kehamilan tak kurang dari 9 bulan hingga 24 bulan sejak kelahiran pertama (Agus Supriyadi, $2005:$ 1).

b. Faktor Penyebab Jarak Persalinan

b. Jarak Persalinan Aman

Jarak ideal untuk kehamilan yaitu tidak kurang dari 2 tahun dan lebih dari 5 tahun. Namun untuk jarak 2 tahun masih terdapat prasyarat, asalkan nutrisi ibu baik. "Bila gizi ibu tidak bagus, berarti tubuhnya belum cukup prima untuk kehamilan berikutnya".

Perhitungan tidak kurang dari 9 bulan ini atas dasar pertimbangan kembalinya organ-organ reproduksi pada keadaan semula. Makanya ada istilah masa nifas, yaitu masa organ-organ reproduksi kembali ke masa sebelum hamil. Namun masa nifas berlangsung hanya empat puluh hari, sementara organ-organ reproduksi baru kembali pada keadaan semula minimal 3 bulan.

1) Faktor-faktor yang mempengarui jarak persalinan yaitu :

a) Keadaan uterus

Uterus sewaktu tidak hamil beratnya hanya $30 \mathrm{~g}$. Setelah hamil, beratnya hampir

$1 \mathrm{~kg}$ atau $1000 \mathrm{~g}$. Kenaikannya hampir 30 kali lipat. Setelah persalinan, beratnya berkurang mencapai $60 \mathrm{~g}$, untuk mencapai $30 \mathrm{~g}$ kembali butuh waktu kira-kira 3 bulan.

b) Sistem aliran darah

Selama hamil, ada sistem aliran darah dari ibu ke janin. Setelah lahir, tentunya aliran darah ini terputus. Untuk kembali ke kondisi aliran darah yang normal, ibu butuh waktu sekitar 15 hari setelah melahirkan.

c) Gizi ibu selama hamil

Untuk memulihkan energi, ibu harus meningkatkan gizinya. Energi baru benarbenar prima seperti keadaan sebelum melahirkan setelah 9 bulan. Kalau belum 9 bulan, belum begitu prima energi ibu walaupun kelihatan tubuhnya sehat-sehat saja.

2) Jarak Terlalu Dekat ( $<2$ tahun)

Jarak kehamilan terlalu pendek atau kurang dari 9 bulan akan sangat berbahaya, karena organ-organ reproduksi seperti : uterus, serviks, vulva, perineum, dan sistem perkemihan belum kembali kekondisi semula. Ibu harus menjaga kondisi kehamilannya dengan lebih intensif, artinya, kehamilan tersebut harus terus dipantau lebih ketat. Seperti pada trimester I dan II dilakukan sebulan sekali, saat menginjak usia kehamilan 28 minggu 3 minggu sekali, di usia kehamilan 32 minggu dilakukan pemeriksaan 2 minggu sekali, dan setelah usia kehamilan 38 minggu seminggu sekali. Resiko jarak perrsalinan apabila terlalu dekat antara lain :

a) Keadaan Gizi Ibu 
Keadaan gizi ibu yang belum prima ini membuat gizi janinnya juga sedikit, hingga pertumbuhan janinnya tak memadai yang dikenal dengan istilah PJT atau pertumbuhan janin terhambat.

b) Kelahiran Premature

Kemungkinan kelahiran prematur juga bisa terjadi pada kehamilan jarak dekat, terutama bila kondisi ibu juga belum begitu bagus. Padahal, kelahiran prematur erat kaitannya dengan kematian, khususnya jika paru-paru bayi belum terbentuk sempurna.

c) Plasenta Previa

Plasenta previa sangat erat kaitannya dengan gizi yang rendah, karena plasenta punya kecenderungan mencari tempat yang banyak nutrisinya. Kalau yang banyak nutrisinya itu terletak di bagian bawah uterus atau rahim, maka di situlah ia akan menempel. Akibatnya bisa menutup jalan lahir yang memungkinkan untuk terjadi perdarahan.

d) Kekurangan Gizi

Pada kehamilan jarak dekat, kemungkinan kekurangan gizi ini amat besar sebab ibu masih menyusui bayinya. Dengan demikian nutrisi ibu jadi berkurang, hingga janinnya juga bisa semakin kekurangan gizi. Oeh karena itu, jika ketahuan hamil, pemberian ASI sebaiknya segera dihentikan. Karena dapat mengakibatkan keguguran. Selama menyusui, ada pengaruh oksitosin pada isapan mulut bayi. Oksitosin ini membuat perut ibu jadi tegang atau kontraksi. Pada kehamilan muda, bisa terjadi perdarahan atau ancaman keguguran.

e) Partus Lama

Jika ibu bisa mempertahankan kehamilannya hingga waktu persalinan tiba, tidak berarti aman-aman saja. Soalnya, bukan tak mungkin kendala justru menghadang saat persalinan. Bahayanya, ibu mengalami kelelahan saat proses persalinan. Untuk mengejan dan hisnya juga susah. Hingga bisa menimbulkan partus atau persalinan lebih lama (Agus Supriyadi, 2005 : 5).

f) Perdarahan Post Partum

Jarak persalinan kurang dari 2 tahum beresiko terjadinya perdarahan post partum, Hal ini disebabkan karena organ-organ reproduksi yang belum kembali ke kondisi semula, sehingga dapat menyebabkan terganggunya kontraksi uterus yang memicu terjadinya atonia uteri sehingga menyebabkan perdarahan post partum.

3) Jarak Terlalu Jauh

Jarak kehamilan tidak boleh lebih dari 5 tahun. Seorang ibu juga harus memikirkan usia saat kehamilan berikutnya, berarti ibu masuk dalam kategori resiko tinggi. Sementara usia reproduksi yang paling bagus adalah 20-30 tahun.

Resiko yang dapat terjadi bila jarak persalinan terlalu jauh:

a) Perdarahan Post Partum

Ibu hamil usia di atas 35 tahun punya resiko 4 kali lipat dibanding sebelum usia 35 tahun. Tidak hanya itu, saat persalinan juga berisiko terjadi perdarahan post partum. Hal ini disebabkan otot-otot rahim tak selentur dulu, sehingga saat mengkerut kembali bisa terjadi gangguan yang berisiko terjadi Hemorargi Post Partum (HPP).

b) Preeklamsi dan eklamasi

Risiko terjadi preeklamsi dan eklamsi juga sangat besar, karena terjadi kerusakan sel-sel endotel dan sirkulasi darah ibu ke janin dan plasenta terganggu, hingga suplai makanan dari ibu ke janin terganggu pula.

c) Masalah Psikis

Bahaya lain juga dapat terjadi seperti masalah psikis. Bila saja ibu sudah lupa dengan cara menghadapi kehamilan dan persalinan. Misalnya bagaimana cara mengejan sehingga dapat menimbulkan stress baru lagi (Agus Supriyadi, 2005:7). 


\section{Konsep Dasar Perdarahan Post Partum}

a. Definisi :

1) Perdarahan post partum adalah perdarahan yang terjadi dalam 24 jam setelah persalinan berlangsung (Hanifa, 2005 : 188).

2) Perdarahan post partum adalah kehilangan $500 \mathrm{ml}$ darah atau lebih setelah kelahiran pervaginam (Bobak dkk, 2004 : 663).

3) Perdarahan post partum adalah kehilangan darah sebanyak $500 \mathrm{ml}$ atau lebih dari traktus genetalis setelah melahirkan (WHO, 2002 : 44).

4) HPP biasanya kehilangan darah lebih dari $500 \mathrm{ml}$ selama atau setelah kelahiran (Dongoes, $2001: 54$ ).

b. Pembagian Perdarahan Post Partum

Perdarahan post partum di bagi menjadi 2 yaitu :

1) Perdarahan post partum dini/primer terjadi dalam 24 jam pertama setelah melahirkan (early post partum hemorrhage). Hampir selalu disebabkan karena atonia uteri, laserasi jalan lahir, retensio plasenta, dan sisa plasenta (Bobak dkk, 2004 : 664).

Penyebab :

a) Uterus atonik terjadi karena plasenta, selaput ketuban tertahan dan overdistensi uterus

b) Trauma genital (meliputi penyebab spontan dan trauma akibat penetalaksanaan/gangguan). Misalnya kelahiran yang menggunakan peralatan termasuk SC dan episiotomi.

c) Kolagulasi intravaskuler desiminata (jarang terjadi)

d) Invertio Uteri (jarang terjadi)

2) Perdarahan post partum lanjut/sekunder terjadi 24 jam setelah melahirkan sampai hari ke 28 post partum (late post partum hemorrhage). Paling umum merupakan akibat sub involusio tempat plasenta, jaringan plasenta tertahan atau infeksi (Bobak dkk, 2004 : 664).

Penyebab :

a) Fragmen plasenta/selaput ketuban tertahan

b) Pelepasan jaringan mati setelah persalinan macet (dapat terjadi di servik, vagina, kandung kamih, dan rektum)

3) Terbukanya luka pada uterus (setelah SC atau rupture uteri)

c. Etiologi

Kehilangan darah terjadi akibat arterial spiral miometrium dan vena desi dua sebelumnya di drainase ruang intervilus palsenta karena kontraksi dalam rahim yang sebagian kosong menyebabkan perusakan plasenta, terjadilah perdarahan dan berlanjut hingga otot rahim berkontaksi disekitar pembuluh darah dan bekerja sebagai pengikat fisiologik anatomi. Kegagalan kontraksi rahim setelah pemisahan plasenta (atonia uteri) mengakibatkan perdarahan yang berlalu banyak di tempat plasenta (Hacker, 2001: 319).

Perdarahan pada suatu tempat didalam tubuh baru terjadi jika keutuhan pembuluh darah terganggu atau terbuka dan mekanisme pembekuan darah tidak mampu membendungnya. Frekuensi perdarahan post partum $4 / 5 \%-15 \%$ dari seluruh persalinan berdasarkan penyebabnya :

1) Atonia Uteri (50\%-60\%)

Akibat kurangnya kuatnya otot-otot uterus untuk berkontraksi sehingga menyebabkan pembuluh darah dan bekas perlekatan plasenta terbuka sehingga perdarahan terus menerus. Faktor predisposisinya adalah :

a) Umur yang terlalu tua atau muda

b) Paritas, sering dijumpai pada multipara dan grandemulti

c) Partus lama dan partus terlantar

d) Uterus yang terlalu tegang : gemeli, hidramnion dan janin besar

e) Obstetrik operatif dan narkosa 
f) Keluhan pada uterus seperti mioma uteri

g) Faktor sosial, ekonomi dan nutrisi

h) Keadaan anemia

2) Retensio Plasenta (16\%-17 \%)

Retensio plasenta adalah tertahannya sisa plasenta melebihi 30 menit setelah bayi lahir (Prawiroharjo, $2005: 656$ ).

Akibat-akibat dari retensio plasenta adalah :

a) Plasenta belum terlepas dari dinding rahim karena tambah melekat lebih dalam.

b) Plasenta sudah lepas tetapi belum keluar karena atonia uterus atau akan menyebabkan perdarahan banyak karena adanya lingkaran konstriksi dan pada bagian segmen bawah rahim akibat kesalahan penanganan kala III yang akan mengahalangi plasenta keluar. Retensio plasenta bsa terjadi seluruh atau sebagian plasenta masuk terdapat di dalam rahim sehingga akan mengganggu kontraksi dan retraksi menyebabkan sinus-sinus darah tetap terbuka menimbulkan terjadinya perdarahan post partum, begitu bagian plasenta terlepas dari dinding rahim, maka perdarahan terjadi di bagian tersebut bagian plasenta yang masih melekat, mengimbangi retraksi miometrium dan perdarahan berlangsung sampai sisa plasenta tersebut terlepas seluruhnya.

3) Sisa plasenta dan selaput ketuban (23\%-24\%)

Sisa plasenta atau selaput janin yang menghalangi kontraksi uterus sehingga masih ada perdarahan yang tetap terbuka dan akan menyebabkan terjadinya perdarahan (Sarwono, 2005 : 189).

Perdarahan post partum dapat terjadi sebagai akibat tertinggalnya sisa plasenta atau selaput janin. Bila hal tersebut terjadi harus segera di keluarkan secara manual atau dikiret dan disusul dengan pemberian obat-obatan oksitosin intravena (Sarwono, 2005:197).

4) Robekan jalan lahir (5\%-6\%)

Perlukaan jalan lahir karena persalinan dapat mengenai perineum, vulva, vagina dan uterus. Jenis perlukaan ringan berupa luka lecet, yang berat berupa suatu robekan yang disertai perdarahan hebat. Pada primigravida yang melahirkan bayi cukup bulan, perlukan jalan lahir tidak dapat dihindarkan (Sarwono, $2005: 409$ ).

Pada umumnya luka yang kecil dan supervisial tidak terjadi perdarahan yang banyak, akan tetapi jika robekan jalan lahir lebar dan dalam, lebih-lebih jika mengenai pembuluh darah menimbulkan perdarahan yang hebat (Sarwono, $2005: 180$ ).

Adapun perlukaan jalan lahir dapat terjadi pada :

a) Dasar panggul berupa episiotomi atau robekan perineum spontan

b) Vulva dan vagina

c) Serviks uteri

d) Uterus

5) Kelainan darah $(0,4 \%-0,6 \%)$

Kelainan pembekuan darah misalnya afibrinogenemia atau hipofibrinogenemia. Tanda-tanda yang sering dijumpai :

a) Perdarahan yang banyak

b) Solusio plasenta

c) Kematian janin yang lama dalam kandungan

d) Pre eklamsi dan eklamsi

e) Infeksi, hepatitis dan syok septik

Penyakit darah seperti anemia berat yang tidak di obati selama kehamilan tua dapat menyebabkan partus lama, perdarahan dan infeksi. Perdarahan dapat disebabkan oleh gangguan pembekuan darah karena meningkatnya aktifitas fibrinilitik dan turunnya kadar fibrinogen serum (Sarwono, 2002 : 458).

d. Faktor predisposisi yang menyebabkan perdarahan post partum adalah sebagai berikut : 
1) Anemia

Seseorang baik pria maupun wanita, dinyatakan menderita anemia apabila kadar hemoglobin dalam darahnya kurang dari $12 \mathrm{gr} / 100 \mathrm{ml}$. Anemia lebih sering dijumpai dalam kehamilan. Keperluan akan zat-zat makanan bertambah dan terjadi pula perubahan-perubahan dalam darah dan sumsum tulang untuk wanita hamil yang memiliki $\mathrm{Hb}$ kurang dari $10 \mathrm{gr} / 100 \mathrm{ml}$ barulah dikatakan menderita anemia dalam kehamilan (Hanifa, $2005:$ 448).

Anemia akan membuat maternal merasa lelah dan kurang mampu merawat dirinya sendiri, meyusui dan memberi makan bayinya serta keluarganya. Hal tersebut akan mempengaruhi kesehatan dan keamanan seluruh keluarga (WHO, 2002 : 46).

Berbagai penyulit dapat timbul karena anemia seperti :
a) Abortus
b) Partus premature
c) Partus lama karena inertia uteri
d) Perdarahan post partum karena atonia
e) Syok
f) Infeksi

(Hanifa, $2005:$ 45).

2) Overdistensi uterus
a) Gemeli
Kehamilan kembar adalah salah satu kehamilan dengan 2 janin atau lebih. Bahaya bagi ibu pada kehamilan kembar lebih besar dari pada kehamilan tunggal, kerena sering terjadi anemia, pre eklamsi dan eklamsi, operasi obstetric dan perdarahan post partum (Hanifa, $2005: 396$ ).
b) Hidramnion
Hidramnion adalah suatu keadaan dimana jumlah air ketuban lebih banyak dari normal, biasanya lebih dari 2 liter. Hidramnion berpotensi terjadi atonia uteri yang berakibat pada perdarahan post partum karena peregangan uterus yang berlebihan (Hanifa, $2005: 252$ ).
c) Janin besar (janin > 4000 gr)

3) Multi paritas

Uterus yang melahirkan banyak anak cenderung bekerja tidak efisien dalam semua kala dalam persalinan.

Karena ibu sering melahirkan, maka, kemungkinan akan di temui keadaan kesehatan terganggu anemia, kurang gizi, kekendoran dinding perut, tampak ibu dengan perut menggantung, kekendoran dinding rahim, sedangkan bahaya yang dapat terjadi antara lain adalah kelainan letak, robekan rahim pada kelainan lintang persalinan lama, perdarahan pasca persalinan (Rochjati, $2003: 60$ ).

4) Jarak persalinan

Jarak persalinan yang sehat adalah 2-5 tahun. Yang mana dapat mengembalikan fungsi-fungsi organ kandungan (involusio). Jika jarak persalinan kurang dari 2 tahun atau lebih dari 5 tahun, maka dapat mengakibatkan berbagai macam penyulit terutama untuk kesehatan fisik dan rahim yang masih belum cukup istirahat dan pemulihan kesehatan secara keseluruhan. Apabila berlanjut dapat mengakibatkan kematian maternal 2 1/5 kali lebih besar (Rochjati, 2003: 56).

5) Persalinan lama

Persalinan lama dapat menyebabkan kelelahan. Bukan hanya rahim yang lelah cenderung berkonsentrsi lemah setelah melahirkan. Tetapi juga ibu yang keletihan kurang mampu bertahan terhadap kehilangan darah (Oxorn, 2003 : 414).

6) Persalinan dengan tindakan narkosa

Melahirkan dengan tindakan ini mencakup prosedur terhadap prosedur operatif seperti forcep tengah dan versi ekstraksi yang mempunyai komplikasi perdarahan. 
Anastesi inhalasi yang dalam dan lama merupakan faktor yang sering menjadi penyebab terjadinya relaksasi miometrium yang menjadi penyebab terjadinya kontraksi serta retraksi atonia uteri dan perdarahan post partum (Oxorn, 2003 : 419).

e Manifestasi klinis

Perdarahan post partum perlu diperhatikan ada perdarahan yang membuat hipotensi dan anemia. Apabila dibiarkan terus pasien akan jatuh dalan keadaan syok. Perdarahan yang terjadi dapat deras dan merembes saja, perdarahan yeng deras biasanya akan segera menarik perhatian, sehingga cepat ditangani. Sedangkan perdarahan yang merembes karena kurang nampak sering kali tidak mendapat perhatian yang seharusnya. Perdarahan yang bersifat merembes ini bila berlangsung lama akan mengakibatkan kehilangan darah yang banyak. Untuk menentukan jumlah perdarahan, maka darah yang keluar setelah uri lahir harus dicatat dan ditampung. Kadang-kadang perdarahan tidak terjadi keluar dari vagina, tetapi menumpuk di vagina dan di dalam uterus. Keadaan ini biasanya diketahui karena adanya kenaikan dari tingginya fundus uteri setelah uri lahir (Hanifa, 2005 : 189).

Gejala klinis umum yang terjadi adalah kehilangan darah dalam jumlah banyak (>500 ml), nadi lemah, pucat, lokhe berwarna merah, haus, pusing, gelisah, letih, dan dapat terjadi syok hipovolemik, tekanan darah rendah, ekstremitas dingin, dan mual.

1) Gejala klinis perdarahan post partum
a) Perdarahan pervaginam
b) Konsistensi rahim lunak
c) Fundus uteri naik (kalau pengaliran darah terhalang oleh bekuan darah atau selaput janin)

2) Tanda-tanda syok

f. Diagnosis

Tabel 42. Diagnosis perdarahan post partum

\begin{tabular}{|c|c|c|}
\hline Gejala dan tanda yang selalu ada & $\begin{array}{c}\text { Gejala dan tanda yang } \\
\text { kadang ada }\end{array}$ & $\begin{array}{c}\text { Diagosis } \\
\text { kemungkinan }\end{array}$ \\
\hline $\begin{array}{ll}\text { a. } & \text { Uterus tidak berkontraksi dan } \\
\text { lembek } \\
\text { b. Perdarahan segera setelah anak } \\
\text { lahir (perdarahan pasca } \\
\text { perdarahan primer) }\end{array}$ & a. Syok & Atonia Uteri \\
\hline $\begin{array}{l}\text { a. Perdarahan segera } \\
\text { b. Darah segar yang mengalir } \\
\text { segera setelah anak lahir } \\
\text { c. Uterus berkontraksi baik } \\
\text { d. plasenta lengkap }\end{array}$ & $\begin{array}{l}\text { a. Pucat } \\
\text { b. Lemah } \\
\text { c. Menggigil }\end{array}$ & $\begin{array}{l}\text { Robekan Jalan } \\
\text { Lahir }\end{array}$ \\
\hline $\begin{array}{l}\text { a. Plasenta belum lahir setelah } 30 \\
\text { menit } \\
\text { b. Perdarahan segera }\end{array}$ & $\begin{array}{l}\text { a. tali pusat putus akibat } \\
\text { traksi berlebih } \\
\text { b. invertia uteri akibat } \\
\text { tarikan } \\
\text { c. perdarahan berlanjut }\end{array}$ & $\begin{array}{l}\text { Retensio } \\
\text { plasenta }\end{array}$ \\
\hline $\begin{array}{l}\text { a. Plasenta/sebagian selaput } \\
\text { (pembuluh darah tidak lengkap) } \\
\text { b. Perdarahan segera }\end{array}$ & $\begin{array}{l}\text { a. Uterus berkontraksi } \\
\text { tetapi tinggi fundus uteri } \\
\text { tidak berkurang }\end{array}$ & $\begin{array}{l}\text { Tertinggalnya } \\
\text { sebagian } \\
\text { plasenta }\end{array}$ \\
\hline $\begin{array}{ll}\text { a. } & \text { Uterus tidak teraba } \\
\text { b. Lumen vagina teraba masa } \\
\text { c. Tampak tali pusat (jika plasenta } \\
\text { lahir) } \\
\text { d. Nyeri sedikit atau berat }\end{array}$ & $\begin{array}{ll}\text { a. } & \text { Syok neurogenik } \\
\text { b. } & \text { Pucat dan limbung }\end{array}$ & Invertio Uteri \\
\hline
\end{tabular}




\begin{tabular}{|c|c|c|}
\hline $\begin{array}{ll}\text { a. } & \text { Sub involusio uterus } \\
\text { b. Nyeri tekan perut bagian bawah } \\
\text { c. } \\
\text { Perdarahan > } 24 \text { jam setelah } \\
\text { persalinan, perdarahan sekunder, } \\
\text { perdarahan bervariasi } \\
\text { (ringan/berat, terus/tidak teratur } \\
\text { dan berbau/infeksi) }\end{array}$ & $\begin{array}{ll}\text { a. Anemia } \\
\text { b. Demam }\end{array}$ & $\begin{array}{l}\text { Perdarahan } \\
\text { terlambat } \\
\text { endometritis/sisa } \\
\text { plasenta } \\
\text { (terinfeksi atau } \\
\text { tidak) }\end{array}$ \\
\hline
\end{tabular}

(Syaifuddin, $2005:$ 175)

g. Penanganan dan pencegahan perdarahan post partum

1) Pencegahan perdarahan post partum

Mencegah atau sekurang-kurangnya bersikap siaga pada kasus-kasus yang di sangka terjadi peradarahan adalah penting. Tindakan peradarahan tidak hanya dilakukan sewaktu bersalin, namun dimulai sejak hamil dengan melaksanakan antenatal care dengan baik. Ibu yang mempunyai predisposisi atau riwayat perdarahan post partum sangan di anjurkan untuk bersalin di rumah sakit.

2) Penanganan umum
a) Meminta bantuan segera mobilisasi seluruh tenaga yang ada sampai UGD
b) Melakukan pemeriksaan secara tepat keadaan ibu termasuk tanda-tanda vital
c) Tanda-tanda syok terlihat, evaluasi cepat, kemudian tangai syok
d) Pastikan kontraksi uterus baik
e) Pasang infuse cairan intravena
f) Kateter atau pantau cairan keluar dan cairan masuk
g) Periksa kelengkapan plasenta
h) Periksa robekan serviks, vagina dan perineum
i) Uji darah

Untuk daerah terpencil dimana terdapat bidan, maka bidan melakukan tindakan dengan urutan :
a) Pasang infuse
b) Pemberian uterotonuka intravena 3-5 unit oksitosin/ergometrin 0,5 - $1 \mathrm{cc}$
c) Kosongkan kandung kemih dan masase uterus (fundus )
d) Menekan uterus ( perasat crede )
e) Periksa apa masih ada plasenta yang tertinggal
f) Bila masih berdarah dalam keadaan darurat dapat melakukan penekanan pada fundus uteri/kompresi bimanual.

\section{METODE PENELITIAN}

\section{Desain Penelitian}

Jenis penelitian ini adalah Analitik. Rancang bangun penelitian yang digunakan adalah Studi Cross Sectional yang merupakan rancangan penelitian pada saat bersamaan (sekali waktu) antara faktor resiko/paparan dengan penyakit (Hidayat, 2007 : 56). Dalam penelitian ini yang dimaksud dengan faktor resiko adalah jarak persalinan dan perdarahan post partum sebagai efeknya

\section{Hipotesis}

Menurut Notoatmodjo (2005) hipotesis adalah suatu jawaban sementara dari pertanyaan penelitian yang dirumuskan dalam bentuk hubungan antara dua variabel dan merupakan pernyataan yang harus dibuktikan.

Hipotesis dalam penelitian ini adalah :

$\mathrm{H}_{1}$ : Ada hubungan jarak persalinan dengan perdarahan post partum di Rumah Bersalin Medika

Utama, Wonokupang Kecamatan Balongbendo Kabupaten Sidoarjo tahun 2009.

\section{Variabel Dan Definisi Operasional}

Variabel independen adalah variabel yang menjadi sebab perubahan atau timbulnya variabel dependen (terikat). Variabel ini dikenal dengan nama variabel bebas dalam 
mempengaruhi variabel lain (Hidayat, 2007 : 37). Variabel independen/variabel bebas dalam penelitian ini adalah jarak persalinan.

Variabel dependen adalah variabel yang dipengaruhi/dapat berubah akibat pengaruh variabel independen (Hidayat, 2007 : 37). Variabel dependen/variabel terikat dalam penelitian ini adalah perdarahan post partum.

Tabel 43. Definisi Operasional Hubungan Jarak Persalinan Dengan Perdarahan Post Partum Di Rumah Bersalin Medika Utama Wonokupang, Kecamatann Balongbendo, Kabupaten Sidoarjo Tahun 2009

\begin{tabular}{|c|c|c|c|}
\hline Variabel & Definisi Operasional & Kriteria & Skala \\
\hline $\begin{array}{l}\text { Independen : jarak } \\
\text { persalinan }\end{array}$ & $\begin{array}{l}\text { Jarak atau interval antara } \\
\text { persalinan terakhir dengan } \\
\text { kehamilan sekarang } \\
\text { (Mufdlilah, 2009: 71). } \\
\text { Alat ukur yang digunakan } \\
\text { yaitu format pengumpulan data } \\
\text { (cheklist) }\end{array}$ & $\begin{array}{l}\text { Jarak }<2 \text { tahun : } 1 \\
\text { Jarak } \geq 2 \text { tahun : } 2 \\
\text { (Poedji Rochjati, } \\
\text { 2003:56) }\end{array}$ & Nominal \\
\hline $\begin{array}{l}\text { Dependen : } \\
\text { Perdarahan post } \\
\text { partum }\end{array}$ & $\begin{array}{l}\text { Kehilangan darah lebih dari } \\
500 \text { ml selama atau setelah } \\
\text { kelahiran. } \\
\text { (Dongoes, } 2001: 54 \text { ) } \\
\text { Alat ukur yang digunakan } \\
\text { yaitu format pengumpulan data } \\
\text { (cheklist) }\end{array}$ & $\begin{array}{l}\text { 1. Ibu bersalin dengan } \\
\text { HPP } \geq 500 \mathrm{ml}: 1 \\
\text { 2. Ibu bersalin dengan } \\
\text { tidak HPP }<500 \mathrm{ml} \\
: 2 \\
\text { (Dongoes, } 2001: 54 \text { ) }\end{array}$ & Nominal \\
\hline
\end{tabular}

4. Populasi, Sampel Dan Instrumen Penelitian

Populasi dalam penelitian ini adalah semua ibu bersalin di Rumah Bersalin Medika Utama, Wonokupang Kecamatan Balongbendo Kabupaten Sidoarjo pada 1 Januari-31 Desember 2009 sebanyak 386 ibu bersalin.

Sampel yang di gunakan dalam penelitian ini adalah Non Probability Sampling dengan teknik Total sampling, yaitu mengambil seluruh anggota populasi sebagai sampel. Sampel yang di gunakan adalah sebanyak 386 ibu bersalin pada pada 1 Januari - 31 Desember 2009 .

Teknik dalam pengumpulan data ini adalah menggunakan teknik observasi sehingga menghasilkan data sekunder. yang di peroleh dari buku register ibu bersalin di Rumah bersalin Medika Utama, Wonokupang Kecamatan Balong Bendo Kabupaten Sidoarjo dari tanggal 1 Januari sampai 31 Desember 2009 dengan menggunakan format pengumpul data (Cheklist) data sekunder dan di tabulasi kemudian dianalisa.

5. Teknik Analisis Data

a. Tahapan univariat

1) Variabel independen (Jarak Persalinan )

Data dalam penelitian ini adalah data nominal, setelah data di peroleh dari register ibu bersalin kemudian data ditabulasikan dan dikelompokkan sesuai dengan sub variabel yang diteliti. Kejadian yang diharapkan diberi kode 1 dan penilaian. Kejadian dengan jarak persalinan $<2$ tahun diberi kode 1 dan jarak persalinan $\geq 2$ tahun diberi kode 2 , kemudian ditabulasi dan dianalisis dengan menggunakan distribusi frekuensi dalam bentuk presentase dengan rumus :

$$
P=\frac{f}{n} x 100 \%
$$

( Budiarto, $2001: 37$ ) 
Keterangan :

$\mathrm{P}$ : Presentase

f : Jumlah frekuensi

$\mathrm{n}$ : Jumlah populasi

2) Variabel dependen (Perdarahan post partum)

Data dalam penelitian ini adalah data nominal, kemudian data dengan jarak persalinan ( $<2$ tahun dan $\geq 2$ tahun) yang mengalami perdarahan post partum yang diperoleh dari register ibu bersalin di beri kode 1 dan yang tidak mengalami perdarahan post partum diberi kode 2, kemudian ditabulasi dan dianalisis dengan menggunakan distribusi frekuensi dalam bentuk presentase.

$$
P=\frac{f}{n} x 100 \%
$$

(Budiarto, $2001: 37$ )

Keterangan :

$\mathrm{P}$ : Presentase

f : Jumlah frekuensi

$\mathrm{n}$ : Jumlah populasi

b. Tahapan bivariat

Dari kedua data tersebut (Jarak persalinan dengan perdarahan post partum) yang keduanya berskala data nominal, maka uji statistik yang di gunakan yaitu uji Chi Squre yaitu melalui rumus sebagai berikut :

$$
\text { rumus } x^{2}=\frac{N(a d-b c) 2}{(a+b)(c+d)(a+c)(b+d)}
$$

Keterangan :

$\mathrm{X}^{2} \quad$ Koefisien korelasi Chi Squre

$\mathrm{N}$ : Nilai sampel

a : Sel a

b : Sel b

c : Sel c

d : Sel d

Data disajikan dalam bentuk tabulasi silang dengan kriteria $\mathrm{X}^{2}$ hitung lebih besar dari $\mathrm{X}^{2}$ tabel, maka $\mathrm{H}_{1}$ di terima, Ho ditolak artinya ada hubungan antara variabel independen dan variabel dependen. Sebaliknya apabila $\mathrm{X}^{2}$ hitung lebih kecil dari $\mathrm{X}^{2}$ tabel, maka $\mathrm{H}_{1}$ ditolak, Ho diterima artinya tida ada hubungan antara variabel independen dan variabel dependen. Tetapi apabila uji Chi Squre tidak terpenuhi yaitu adanya sel dengan frekuensi harapan $<5$, maka dilakukan uji Fisher Exact dengan rumus :

Dimana :

$$
P=\frac{(a+b) !(c+d) !(a+c) !(b+d)}{n ! a ! b ! c ! d}
$$

$\mathrm{a}=$ sel $\mathrm{a}:$ baris 1 kolom 1

$\mathrm{b}=$ sel $\mathrm{b}:$ baris 1 kolom 2

$\mathrm{c}=$ sel $\mathrm{c}:$ baris 2 kolom 1

$\mathrm{d}=$ sel $\mathrm{d}$ : baris 2 kolom 2

Jika nilai $\mathrm{p}<0.05$ maka Ho ditolak, $\mathrm{H}_{1}$ diterima artinya ada hubungan yang bermakna antara variabel independen dan variabel dependen, sebaliknya jika nilai $p>0.05$ maka Ho diterima, $\mathrm{H}_{1}$ ditolak artinya tidak ada hubungan yang bermakna antara variabel independen dan variabel dependen. 
D. HASIL PENELITIAN

1. Data Umum

a. Distribusi frekuensi responden berdasarkan Usia

Tabel 44. Distribusi Frekuensi Ibu Bersalin Berdasarkan Usia di RB Medika Utama Wonokupang Kecamatan Balongbendo Kabupaten Sidoarjo 1 Januari - 31 Desember 2009

\begin{tabular}{|c|l|c|c|}
\hline No. & \multicolumn{1}{|c|}{ Usia } & Jumlah & Presentase (\%) \\
\hline 1. & $<20$ Tahun & 67 & 17,4 \\
2. & 20-30 Tahun & 236 & 61,2 \\
3. & $>$ 30 Tahun & 83 & 21,4 \\
\hline \multicolumn{2}{|c|}{ Jumlah } & $\mathbf{3 8 6}$ & $\mathbf{1 0 0}$ \\
\hline
\end{tabular}

Sumber : Register ibu bersalin RB Medika Utama

Berdasarkan tabel 44 diatas menunjukkan bahwa dari 386 responden sebagaian besar ibu bersalin berusia 20 - 30 Tahun, yaitu sebanyak 236 responden ( 61,2\% ).

b. Distribusi frekuensi responden berdasarkan Pendidikan

Tabel 45. Distribusi Frekuensi Ibu Bersalin Berdasarkan Pendidikan di RB Medika Utama Wonokupang Kecamatan Balongbendo Kabupaten Sidoarjo 1 Januari - 31 Desember 2009

\begin{tabular}{|c|l|c|c|}
\hline No. & \multicolumn{1}{|c|}{ Pendidikan } & Jumlah & Presentase ( \% ) \\
\hline 1. & Tidak sekolah & 5 & 1,1 \\
2. & SD & 115 & 29,8 \\
3. & SMP & 158 & 41,0 \\
4. & SMA/Sederajat & 93 & 24,2 \\
5. & Perguruan Tinggi & 15 & 3,9 \\
\hline \multicolumn{2}{|c|}{ Jumlah } & $\mathbf{3 8 6}$ & $\mathbf{1 0 0}$ \\
\hline
\end{tabular}

Sumber : Register ibu bersalin RB Medika Utama

Berdasarkan tabel 46 diatas menunjukkan bahwa dari 386 responden hampir setengah dari ibu bersalin yang berpendidikan SMP yaitu sebanyak 158 responden $(41,0 \%)$.

c. Distribusi frekuensi responden berdasarkan Pekerjaan

Tabel 46. Distribusi Frekuensi Ibu Bersalin Berdasarkan Pekerjaan di RB Medika Utama Wonokupang Kecamatan Balongbendo Kabupaten Sidoarjo 1 Januari - 31 Desember 2009

\begin{tabular}{|c|l|c|c|}
\hline No. & Pekerjaan & Jumlah & Presentase (\%) \\
\hline 1. & Bekerja & 80 & 20,8 \\
2. & Tidak Bekerja & 306 & 79,2 \\
\hline \multicolumn{2}{|c|}{ Jumlah } & $\mathbf{3 8 6}$ & $\mathbf{1 0 0}$ \\
\hline
\end{tabular}

Sumber : Register ibu bersalin RB Medika Utama

Berdasarkan tabel 46 diatas menunjukkan bahwa dari 386 responden hampir seluruhnya ibu bersalin tidak bekerja yaitu sebanyak 306 responden ( 79,2\% ).

d. Distribusi frekuensi responden berdasarkan Paritas

Tabel 47. Distribusi Frekuensi Ibu Bersalin Berdasarkan Paritas di RB Medika Utama Wonokupang Kecamatan Balongbendo Kabupaten Sidoarjo 1 Januari - 31 Desember 2009

\begin{tabular}{|c|l|c|c|}
\hline No. & \multicolumn{1}{|c|}{ Paritas } & Jumlah & Presentase (\%) \\
\hline 1. & 1 & 150 & 38,8 \\
2. & $2-4$ & 186 & 48,3 \\
3. & $\geq 5$ & 50 & 12,9 \\
\hline \multicolumn{2}{|c|}{ Jumlah } & $\mathbf{3 8 6}$ & $\mathbf{1 0 0}$ \\
\hline
\end{tabular}

Sumber : Register ibu bersalin RB Medika Utama 
Berdasarkan tabel 47 diatas menunjukkan bahwa dari 386 responden hampir setengah ibu

2. Data Khusus

bersalin mempunyai paritas 2-4 yaitu sebanyak 186 responden $(48,3 \%)$.

Data khusus ini menggambarkan tentang jarak persalinan ibu dan ibu bersalin yang mengalami perdarahan post partum, serta tabulasi silang jarak pesalinan ibu dengan perdarahan post partum di Rumah Bersalin Medika Utama Wonokupang Kecamatan Balongbendo Kabupaten Sidoarjo Periode 1 Januari sampai 31 Desember 2009.

a. Jarak Persalinan

Berikut ini di sajikan tabel mengenai kejadian jarak persalinan ibu di Rumah Bersalin Medika Utama Wonokupang Kecamatan Balongbendo Kabupaten Sidoarjo 1 Januari - 31 Desember 2009

Tabel 48. Distribusi Frekuensi Relatif Kejadian Jarak Persalinan Ibu di RB Medika Utama Wonokupang Kecamatan Balongbendo Kabupaten Sidoarjo 1 Januari - 31 Desember 2009

\begin{tabular}{|c|c|c|c|}
\hline No. & Jarak Persalinan & Jumlah & Presentase (\%) \\
\hline 1. & $<2$ tahun & 42 & 10,8 \\
2. & $\geq 2$ tahun & 344 & 89,2 \\
\hline \multicolumn{2}{|c|}{ Jumlah } & $\mathbf{3 8 6}$ & $\mathbf{1 0 0}$ \\
\hline
\end{tabular}

Sumber : Register ibu bersalin RB Medika Utama

Berdasarkan tabel 48 diatas menunjukkan bahwa hampir seluruhnya responden ibu bersalin mempunyai jarak persalinan $\geq 2$ tahun yaitu sebanyak 344 responden $(89,2 \%)$

b. Perdarahan Post Partum

Berikut ini di sajikan tabel mengenai kejadian perdarahan post partum di Rumah Bersalin Medika Utama Wonokupang Kecamatan Balongbendo Kabupaten Sidoarjo Tahun 2009

Tabel 49. Distribusi frekuensi Relatif Kejadian Perdarahan Post Partum di RB Medika Utama Wonokupang Kecamatan Balongbendo Kabupaten Sidoarjo 1 Januari - 31 Desember 2009

\begin{tabular}{|c|l|c|c|}
\hline No. & \multicolumn{1}{|c|}{ Perdarahan Post Partum } & Jumlah & Presentase(\%) \\
\hline 1. & Perdarahan post partum $\geq 500 \mathrm{ml}$ & 33 & 8,6 \\
2. & Tidak perdarahan post partum $<500 \mathrm{ml}$ & 353 & 91,4 \\
\hline \multicolumn{2}{|c|}{ Jumlah } & $\mathbf{3 8 6}$ & $\mathbf{1 0 0}$ \\
\hline
\end{tabular}

Sumber : Register ibu bersalin RB Medika Utama

Berdasarkan tabel 49 diatas menunjukkan bahwa dari 386 responden hampir seluruhnya ibu bersalin tidak terjadi perdarahan post partum yaitu sebanyak 353 responden $(91,4 \%)$.

c. Hubungan jarak persalinan dengan perdarahan post partum

Berikut ini akan di sajikan keterkaitan antara kedua variabel yaitu jarak persalinan dengan perdarahan post partum di Rumah Bersalin Medika Utama Wonokupang Kecamatan Balongbendo Kabupaten Sidoarjo Tahun 2009

Tabel 50. Tabulasi Silang jarak persalinan Dengan Perdarahan Post Partum di RB Medika Utama Wonokupang Kecamatan Balongbendo Kabupaten Sidoarjo 1 Januari - 31 Desember 2009

\begin{tabular}{|c|c|c|c|c|c|c|c|}
\hline & \multicolumn{4}{|c|}{ Perdarahan Post Partum } & \multicolumn{2}{|c|}{ Jumlah } \\
\hline & & Ya & $(\%)$ & Tidak & $(\%)$ & Total & $(\%)$ \\
\hline \multirow[t]{2}{*}{ Jarak Persalinan } & $<2$ thn & 12 & 3,1 & 30 & 7,7 & 42 & 10,8 \\
\hline & $\geq 2$ thn & 21 & 5,5 & 323 & 83,7 & 344 & 89,2 \\
\hline \multicolumn{2}{|l|}{ Jumlah } & 33 & 8,6 & 353 & 91,4 & 386 & 100 \\
\hline
\end{tabular}


Berdasarkan tabel 50 menunjukkan bahwa dari 386 responden hampir seluruhnya yang memiliki jarak pesalinan $\geq 2$ thn dan tidak mengalami perdarahan post partum yaitu 323 responden $(83,7 \%)$.

Untuk mengetahui hubungan antara jarak persalinan dengan perdarahan post partum maka dilakukan uji statistik dengan menggunakan uji Chi Square, karena dengan menggunakan uji Chi Square tidak terpenuhi yaitu adanya sel dengan frekuensi harapan $<5$, maka dilakukan uji Fisher Exact yaitu dengan hasil $p=0,000$.Karena nilai uji Fisher exact $0,000<\mathrm{p}<0,05$ maka Ho ditolak, $\mathrm{H}_{1}$ diterima artinya ada hubungan yang bermakna antara variabel independen (jarak persalinan) dan variabel dependen ( perdarahan post partum ).

\section{E. PEMBAHASAN}

1. Jarak Persalinan

Berdasarkan tabel diatas menunjukkan bahwa hampir seluruh responden ibu bersalin mempunyai jarak persalinan $\geq 2$ tahun yaitu sebanyak 344 responden $(89,2 \%)$.

Menurut Poedjirochyati (2003 : 56) jarak persalinan adalah salah satu penyebab perdarahan post partum yang bisa berakhir dengan kematian ibu. Apabila jarak persalinan terlalu dekat ( $<2$ tahun) atau terlalu jauh lebih dari 5 tahun akan sangat berbahaya karena hal tersebut dapat memicu terjadinya perdarahan.

Berdasarkan data diatas banyak faktor yang mempengarui jarak persalinan antara lain ada faktor usia, paritas, dan pendidikan. Hal ini dapat dapat ditunjukkan dari data yang diperoleh dengan jarak persalinan kurang dari 2 tahun sebagian kecil ibu mempunyai paritas (24) yaitu sebanyak 21 responden (3,9\%), dari segi usia responden sebagian kecil ibu bersalin berusia 20-30 yaitu tahun sebanyak 21 responden $(4,7 \%)$, dari segi pendidikan sebagian kecil ibu bersalin berpendidikan SD yaitu 15 respoden $(2,8 \%)$.

Jarak persalinan juga dapat dipengarui oleh umur, pendidikan dan paritas. Apabila ibu hamil pertama dengan umur yang cukup matang, maka ibu dapat mengerti dan mengatur jarak persalinan yang aman yaitu lebih dari dua tahun. Sedangkan dilihat dari segi pendidikan, bila semakin tinggi tingkat pendidikan seorang ibu semakin baik pula tingkat pengetahuannya sehingga ibu dapat mengatur jarak persalinan antara anak pertama dengan anak berikutnya. Kemudian dilihat dari segi paritas bila ibu terlalu sering melahirkan kemungkinan akan ditemui keadaan kesehatan terganggu, seperti anemia, kurang gizi, kekendoran pada dinding perut. Hal ini dapat mempengarui keselamatan dan kesehatan tubuh ibu dan janin.

Hal ini menunjukkan bahwa ibu bersalin perlu mengatur persalinan agar tidak membahayakan kondisi ibu dan janin. Dan dengan digalakkan dengan progam KB dari pemerintah di harapkan untuk semua ibu untuk mengatur jarak persalinan sehingga dapat mengurangi angka kematian ibu dan janin.

\section{Perdarahan Post Partum}

Berdasarkan data hasil penelitian dapatkan bahwa dari 386 responden hampir seluruhnya tidak terjadi perdarahan post partum yaitu sebanyak 353 responden $(96,4 \%)$. Perdarahan post partum merupakan kehilangan darah lebih dari $500 \mathrm{ml}$ melalui jalan lahir yang terjadi selama atau setelah persalinan. Perkiraan kehilangan darah biasanya tidak sebanyak yang sebenarnya. Kadang-kadang hanya setengah dari yang sebenarnya. Darah tersebut tercampur amnion atau urine ( Sarwono, 2005; 450 ).

Berdasarkan hasil penelitian didapatkan faktor lain penyebab terjadinya perdarahan post partum antara lain adalah usia dan paritas. Pada responden dengan usia 20 - 30 tahun sebagaian besar kecil mengalami perdarahan post partum yaitu sebanyak sebanyak 19 responden $(7,1 \%)$. Setiap bertambahnya usia maka terjadi perubahan pada jaringan alat-alat kandungan . Jika usia ibu terlalu muda rahim dan panggul ibu belum tumbuh mencapai ukuran yang dewasa. Akibatnya diragukan keselamatan dan kesehatan janin dalam kandungan. Selain itu juga beresiko terjadi perdarahan setelah bayi lahir. Apabila umur ibu terlalu tua yaitu lebih dari 35 tahun maka akan terjadi kelemahan otot-otot rahim, dan organ kandungan menua sehingga 
kemungkinan dapat terjadi preeklamsia, ketuban pecah dini, persalinan macet, dan perdarahan post partum (Poedjirochyati, $2003: 62$ ).

Pada responden yang paritas 2-4 yaitu sebanyak 16 responden $(4,6 \%)$ mengalami perdarahan post partum. Bila ibu sering melahirkan maka akan terjadi kekendoran pada otot dinding rahim sehingga kondisi ini dapat membahayakan kondisi ibu dan janin. Diantaranya kelainan letak, robekan rahim pada kelainan letak lintang, persalinan lama dan perdarahan post partum (Poedjirochyati, 2003 : 62).

Dari data diatas menunjukkan bahwa ibu bersalin yang usianya lebih tua dan mempunyai paritas tinggi mempunyai pengaruh terhadap perdarahan post partum dikarenakan fungsi pada uterus sudah berkurang. Data ini menunjukkan bahwa usia dan paritas ibu bersalin mempengarui terjadinya perdarahan post partum.

Perdarahan post partum dapat juga timbul karena salah penanganan kala III persalinan dengan memijat uterus dan mendorongnya ke bawah dalam usaha melahirkan plasenta, sedangkan sebenarnya plasenta belum terlepas. Kadang-kadang perdarahan kelaianan proses pembekuan darah akibat dari hipofibrinogenemia (solusio plasenta, retensio plasenta, retensi jani mati dalam uterus, emboli air ketuban). Apabila sebagian plasenta lepas sebagaian lagi belum, terjadi perdarahan karena uterus tidak berkontraksi dengan baik pada batas antara dua bagian itu. Selanjutnya, apabila sebagian besar plasenta sudah lahir tapi sebagaian plasenta masih melekat pada dinding uterus, dapat timbul perdarahan pada masa nifas. Perlukaan jalan lahir yang juga dapat menyebabkan perdarahan sebab terpenting perdarahan post partum adalah atonia uteri. Ini terjadi akibat dari partus lama, pembesaran uterus yang berlebihan pada waktu hamil seperti hamil kemba, hidramnion, atau janin besar, multiparitas, anastesi yang dalam, dan anastesi lumbal. Oleh karena itu perdarahan post partum perlu diwaspadai karena dapat menimbulkan kematian pada ibu.

\section{Hubungan Jarak persalinan dengan perdarahan post partum}

Berdasarkan tebel diats dapat di ketahui bahwa dari 386 responden sebagian kecil ibu bersalin yang memiliki jarak persalinan kurang dari 2 tahun yaitu sebanyak 12 responden $(3,1 \%)$ yang mengalami perdarahan post partum. Dan dibuktikan dengan uji statistik Fisher exact karena frekuensi harapan pada $1 \mathrm{sel}<5$ dan di dapatkan hasil $0,000<\mathrm{p}<0,05$ maka Ho ditolak, $\mathrm{H}_{1}$ diterima artinya ada hubungan yang bermakna variabel independen (Jarak Persalinan) dan variabel dependen (perdarahan post partum ).

Salah satu faktor penyebab perdarahan post partum adalah jarak persalinan. Jarak persalinan yang dekat dapat mempengarui involusi uteri, otot-otot rahim yang kendor, mempengarui tingginya kegagalan konraksi yang menyebabkan pembuluh darah pada bekas implantasi plasenta terbuka yang mengakibatkan perdarahan (Poedjirochyati, $2003: 62$ ). Dari data diatas menunjukkan bahwa jarak persalinan yang $<2$ tahun mempunyai pengaruh terhadap terjadinya perdarahan post partum.

Berdasarkan hasil penelitian ibu yang mempunyai jarak persalinan $\geq 2$ tahun ternyata juga masih terjadi perdarahan post partum hal ini disebabkan oleh beberapa faktor yaitu faktor usia dimana jika usia ibu terlalu muda rahim dan panggul ibu belum tumbuh mencapai ukuran yang dewasa. Sedangkan umur ibu lebih dari 35 tahun, dapat mudah terjadi penyakit pada organ kandungan menua serta jalan lahir juga kaku. Sehingga meski jarak persalinan yang sudah lebih dari 2 tahun masih dapat terjadi perdarahan post partum. Adapun faktor lain yang dapat mempengarui yaitu ibu yang memiliki riwayat penyakit misalnya anemia, preeklamsia dan eklamsia.

Tindakan pencegahan atau sekurang-kurangnya bersikap siaga pada komplikasi persalinan terutama hal yang dapat mengakibatkan perdarahan merupakan hal yang paling penting. Tindakan ini di maksudkan untuk mengurangi kejadian perdarahan selama hamil, bersalin, dan nifas. Pencegahan terhadap terjadinya perdarahan post partum ini tidak hanya dilakukan sewaktu bersalin saja, namun di mulai sejak hamil dengan melaksanakan antenatal care (ANC) dengan baik. Bagi semua ibu yang mempunyai resiko terhadap terjadinya 
perdarahan post partum maupun riwayat perdarahan post partum pada persalinan sebelumnya dianjurkan untuk bersalin di Rumah Sakit.

Selain penanganan obstetrik yang baik di harapkan juga dapat digalakkan program KB (Keluarga Berencana ) dengan alasan program KB dapat mencegah proses kehamilan dan dapat memperpanjang jarak persalinan. Pertolongan yang dapat diberikan oleh ibu diantaranya yaitu diberikan komunikasi, informasi, edukasi agar melakukan perawatan kesehatan yang teratur.

Berdasarkan pembahasan diatas dapat disimpulkan bahwa jarak persalinan mempunyai hubungan dengan perdarahan post partum.

\section{F. PENUTUP}

Berdasarkan hasil penelitian diatas dapat disimpulkan bahwa dari 386 responden hampir seluruhnya ibu bersalin mempunyai jarak persalinan $\geq 2$ tahun yaitu sebanyak 344 responden $(89,2 \%)$, hampir seluruhnya ibu bersalin tidak terjadi perdarahan post partum yaitu sebanyak 353 responden (91,4\%). Dari uji statistik Fisher exact didapatkan hasil 0,000 <p<0,05 maka Ho ditolak, $\mathrm{H}_{1}$ diterima artinya ada hubungan yang bermakna jarak persalinan dengan perdarahan post partum. Tindakan pencegahan atau sekurang-kurangnya bersikap siaga pada komplikasi persalinan terutama hal yang dapat mengakibatkan perdarahan merupakan hal yang paling penting. Tindakan ini di maksudkan untuk mengurangi kejadian perdarahan selama hamil, bersalin, dan nifas. Pencegahan terhadap terjadinya perdarahan post partum ini tidak hanya dilakukan sewaktu bersalin saja, namun di mulai sejak hamil dengan melaksanakan antenatal care (ANC) dengan baik. Bagi semua ibu yang mempunyai resiko terhadap terjadinya perdarahan post partum maupun riwayat perdarahan post partum pada persalinan sebelumnya dianjurkan untuk bersalin di Rumah Sakit.

\section{DAFTAR PUSTAKA}

Admin. (2009). Perdarahan Post Partum. http://medlinux.blogspot.com/2009/02/perdarahan-postpartum.html, diakses tanggal 20 april 2010).

Agus Supriyadi. (2005). Jarak Persalinan Yang Aman. http://andriesalima.multiply.com. diakses pada tanggal 20 April 2010).

Alimul , Aziz.(2007). Metode Penelitian Kebidanan dan Teknik Analisis Data. Jakarta : Salemba Medika.

Arikunto Suharsimi. (2006). Prosedur Penelitian Suatu Pendekatan Praktek. Jakarta. PT Rineka Cipta.

Barbara R Stright. (2005). Keperawatan Ibu Bayi Baru Lahir Edisi 3 . Jakarta . EGC.

Bobak Dkk. (2004). Buku Ajar Keperawatan Maternitas edisi 4 . Jakarta . EGC.

Budiarto eko. (2001) Statistika untuk Kedokteran Dan Kesehatan Masyarakat. Jakarta. EGC.

Carey J Christoper \& William Rayburn. (2001). Obstetri dan Ginekologi. Jakarta . Widya Medika.

Dongoes E Marilyn. (2001). Rencana Asuhan Perawatan Maternitas Dan bayi. Jakarta EGC.

Depkes RI. (2007). Buku Acuan Asuhan persalinan Normal. Jakarta. JNPK-KR.

Depkes. (2009). AKI Dan AKB Di Indonesia (http://www.depkes.go.id diakses tanggal 20 April 2010).

Hellen Varney, Dkk, (2007). Buku Ajar Asuhan Kebidanan . Jakarta . EGC.

Nanda.(2009). Penanganan Perdarahan Post Partum. www.goescities.comdiakses pada tanggal 20 April 2010) .

Notoadmodjo, S. 2005. Metodologi Penelitian Kesehatan Edisi Revisi. Jakarta. PT Rineka Cipta.

Nursalam. (2008). Konsep Dan Rencana Penetapan Metodologi Penelitian Ilmu Keperawatan. Jakarta . Salemba Medika.

Prawiroharjo Sarwono. (2005). Ilmu Kandungan. Jakarta. Yayasan Bina Pustaka Sarwono Prawiroharjo.

Rochjati Poedji. (2003). Skrining Antenatal Pada Ibu Pada Ibu Hamil Dan Pengenalan Faktor Resiko Deteksi Dini Ibu Hamil Resiko Tinggi. Jakarta. Airlangga University Press.

Ruth Johnson \& Wendy Tailor. (2005). Buku Ajar Praktek Kebidanan . Jakarta. EGC 
Syaifudin Abdul Bari. (2005). Acuan Nasional Pelayanan Kesehatan Maternal Noenatal Edisi 1. Jakarta. Yayasan Bina Pustaka Sarwono Prawiroharjo.

Hacker er More. ( 2001 ) Esensial Obstetri Dan Ginekologi. Jakarta. Hipocrates.

WHO. (2002) Safe Motherhood Modul hemorragie Post Partum Materi Pendidikan Bidan. Jakarta. EGC.

William. (2006). Obstetri Williams. Jakarta : EGC. 